\title{
HDAC1 and HDAC2 Control the Specification of Neural Crest Cells into Peripheral Glia
}

\author{
Claire Jacob, ${ }^{1,4 \star}$ Pirmin Lötscher, ${ }^{1 \star}$ Stefanie Engler, ${ }^{1,4}$ Arianna Baggiolini, ${ }^{3}$ Sandra Varum Tavares, ${ }^{3}$ Valérie Brügger, ${ }^{4}$ \\ Nessy John, ${ }^{3}$ Stine Büchmann-Møller, ${ }^{3}$ Paige L. Snider, ${ }^{5}$ Simon J. Conway, ${ }^{5}$ Teppei Yamaguchi, ${ }^{2}$ Patrick Matthias, ${ }^{2}$ \\ Lukas Sommer, ${ }^{3}$ Ned Mantei, ${ }^{1}$ and Ueli Suter ${ }^{1}$ \\ ${ }^{1}$ Institute of Molecular Health Sciences, Department of Biology, ETH Zurich, CH-8093 Zurich, Switzerland, ${ }^{2}$ FMI for Biomedical Research, Novartis \\ Research Foundation, CH-4058 Basel, Switzerland, ${ }^{3}$ Institute of Anatomy, University of Zurich, CH-8057 Zurich, Switzerland, ${ }^{4}$ Institute of Zoology, \\ Department of Biology, University of Fribourg, CH-1700 Fribourg, Switzerland, and 5 Developmental Biology and Neonatal Medicine Program, H.B. Wells \\ Center for Pediatric Research, Indiana University School of Medicine, Indianapolis, Indiana 46202
}

Schwann cells, the myelinating glia of the peripheral nervous system (PNS), originate from multipotent neural crest cells that also give rise to other cells, including neurons, melanocytes, chondrocytes, and smooth muscle cells. The transcription factor Sox 10 is required for peripheral glia specification. However, all neural crest cells express Sox 10 and the mechanisms directing neural crest cells into a specific lineage are poorly understood. We show here that histone deacetylases 1 and $2(\mathrm{HDAC1} / 2)$ are essential for the specification of neural crest cells into Schwann cell precursors and satellite glia, which express the early determinants of their lineage myelin protein zero (P0) and/or fatty acid binding protein 7 (Fabp7). In neural crest cells, HDAC1/2 induced expression of the transcription factor Pax 3 by binding and activating the Pax3 promoter. In turn, Pax3 was required to maintain high Sox 10 levels and to trigger expression of Fabp7. In addition, $\mathrm{HDACl} / 2$ were bound to the $P 0$ promoter and activated $P 0$ transcription. Consistently, in vivo genetic deletion of HDAC1/2 in mouse neural crest cells led to strongly decreased Sox 10 expression, no detectable Pax3, virtually no satellite glia, and no Schwann cell precursors in dorsal root ganglia and peripheral nerves. Similarly, in vivo ablation of Pax3 in the mouse neural crest resulted in strongly reduced expression of Sox10 and Fabp7. Therefore, by controlling the expression of Pax3 and the concerted action of Pax3 and Sox10 on their target genes, HDAC1/2 direct the specification of neural crest cells into peripheral glia.

Key words: histone deacetylases; neural crest cells; peripheral glia specification; transcriptional control

\section{Introduction}

Specification of neural crest cells into the Schwann cell lineage is instructed by neuregulin 1 (Shah et al., 1994) and requires the transcription factor Sox10, which induces the expression of the neuregulin receptor ErbB3 (Britsch et al., 2001; Prasad et al., 2011) and of the early determinants of Schwann cell precursors fatty acid binding protein 7 (Fabp7) and myelin protein zero (P0) (Kurtz et al., 1994; Hagedorn et al., 1999; Jessen and Mirsky, 2005). Sox10 is expressed in neural crest cells and remains expressed in peripheral glia, whereas it is downregulated in other

\footnotetext{
Received Dec. 12, 2013; revised March 18, 2014; accepted March 27, 2014.

Author contributions: C.J., P.L., L.S., N.M., and U.S. designed research; C.J., P.L., S.E., A.B., S.V.T., V.B., N.J., S.B.-M., P.L.S., and S.J.C. performed research; C.J.,P.L., S.E., S.J.C., T.Y., and P.M. contributed unpublished reagents/ analytic tools; C.J., P.L., S.E., V.B., and L.S. analyzed data; C.J. and U.S. wrote the paper.

This work was supported by the Swiss National Science Foundation and National Center for Competence in Research Neural Plasticity and Repair (C.J., U.S.), the Novartis Research Foundation (P.M.), and the National Institutes of Health (Grant HL60714 to S.J.C.). We thank B. Weinberg, E. Seto, S. Schreiber, W.J. Pavan, G. Marfany, J. Epstein, E. Campeau, G. Lemke, I. Skerjanc, and M.D. Goulding for providing constructs; A. McMahon and P. Soriano for transgenic animals; and the members of the Suter laboratory for useful discussions.

*C.J. and P.L. contributed equally to this work.

Correspondence should be addressed to either of the following: Dr. Claire Jacob, Department of Biology, Institute of Zoology, University of Fribourg, Chemin du Musée 10, 1700 Fribourg, Switzerland, E-mail: claire.jacob@unifr.ch; or Dr. Ueli Suter, Department of Biology, Institute of Molecular Health Sciences, ETH Hönggerberg, Schafmattstrasse 22, 8093 Zurich, Switzerland, E-mail: usuter@biol.ethz.ch.

DOI:10.1523/JNEUROSCI.5212-13.2014

Copyright $\odot 2014$ the authors $\quad 0270-6474 / 14 / 346112-11 \$ 15.00 / 0$
}

neural crest-derived cells (Kuhlbrodt et al., 1998). Pax3 is another key transcription factor for neural crest cells and several of their derived lineages (Auerbach, 1954). In the absence of Pax3, dorsal root ganglia (DRG) are smaller (Auerbach, 1954; Olaopa et al., 2011) and Schwann cells are strongly reduced in number or absent (Franz, 1990). In the mouse Schwann cell lineage, Pax3 is expressed until embryonic day 13.5 (E13.5) and is then turned off and reexpressed at later stages, where it participates in the control of the Schwann cell cycle (Kioussi et al., 1995; Doddrell et al., 2012).

Although Sox 10 is clearly critical for peripheral glia specification, the mechanisms controlling Sox 10 expression and activity in neural crest cells during this process remain unclear. As for Pax3, canonical Wnt signaling has been shown to activate the Pax3 promoter through Cdx transcription factors in Neuro2a cells (Sanchez-Ferras et al., 2012) to induce sensory neurogenesis and melanocyte formation, but not specification of peripheral glia (Hari et al., 2012). Therefore, the mechanisms regulating Pax3 expression in neural crest cells and Pax3-dependent control of peripheral glia specification are not known.

We investigated the potential involvement of histone deacetylases (HDACs) in this process. HDACs are transcriptional regulators that deacetylate histones to modify chromatin architecture (de Ruijter et al., 2003; Michan et al., 2007) or deacetylate tran- 
scription factors to modulate their activity (Glozak et al., 2005; Yao et al., 2011). Histone deacetylation was long thought to only result in gene silencing by local compaction of the chromatin structure. However, HDACs are also needed to keep genes in an active state (Wang et al., 2009) by acting in concert with histone acetyltransferases (HATs). Therefore, the level of histone acetylation and the presence of HDACs at a gene locus do not always reflect the activity status of a gene. Here, we elucidate HDAC functions in conjunction with their binding partners that allow recruitment to their critical target genes to modulate transcriptional activity. We demonstrate that the highly homologous HDAC1 and HDAC2 are essential for the specification of neural crest cells into Schwann cell precursors and satellite glia. HDAC1/2 induced Pax3 expression in neural crest cells. In turn, Pax3 maintained high Sox10 levels during specification. HDAC1/2 also activated P0 expression in neural crest cells. These mechanisms were necessary for expression of early determinants of Schwann cells and satellite glia and therefore for their specification.

\section{Materials and Methods}

Plasmids. Sox10 shRNA-1 (MISSION shRNA clone reference \#TRCN0000239154; Sigma) and Sox10 shRNA-2 (MISSION shRNA clone reference \#TRCN0000244290; Sigma), Mouse Sox10 MCS1C (plasmid 20240; Addgene; Antonellis et al., 2008), mouse Sox10 MCS4 (kind gift from A. McCallion, Johns Hopkins University School of Medicine, Baltimore, MD), human Fabp7 promoter (kind gift from G. Marfany, Universitat de Barcelona, Barcelona, Spain), rat $P 0$ promoter (kind gift from G. Lemke, The Salk Institute, La Jolla, CA), mouse Pax3 promoter (kind gift from I. Skerjanc, University of Ottawa, Ontario, Canada), pBJ5 HDAC1-overexpression construct (kind gift from S. Schreiber, Broad Institute, Cambridge, MA), pME1 8 S HDAC2-overexpression construct (kind gift from E. Seto, Lee Moffitt Cancer Center and Research Institute, Tampa, FL), Sox10overexpression construct (kind gift from M. Wegner, Universität ErlangenNürnberg, Erlangen, Germany), and Pax3 overexpression construct (Addgene plasmid 27319, Epstein et al., 1995). Constructs for in situ hybridization were as follows: Hdac1 (EST clone, IMAGE ID: 4976514), Hdac2 (mouse full-length cDNA was cloned into the pCMV-Sport6 expression vector), Pax3 (kind gift from M. D. Goulding, The Salk Institute for Biological Studies, La Jolla, CA), P0 (kind gift from G. Lemke, The Salk Institute, La Jolla, CA and R. Axel, Columbia University, New York, NY), and Fabp7 (EST clone, IMAGE ID: 5700428).

Generation of lentiviruses and transduction of JoMal cells. We previously described HDAC1 shRNA and control shRNA lentiviral constructs (Jacob et al., 2011). We designed a mouse HDAC2-specific shRNA and a Pax3-specific shRNA using Dharmacon siDESIGN Center and 2-shRNA Oligo Designer (http://www.unc.edu/ cail/biotool/2shRNA.html).

Targeting sequences were as follows: H2sh, GACCGTCTCATTCCATAAA; Pax3sh, GGAAGGAAGCAGAAGAAAG. We cloned the corresponding shRNA oligonucleotides (synthesized by Microsynth) into pLentiLox 3.7 lentiviral plasmid (ATCC) using either HpaI/XhoI or $\mathrm{HpaI} /$ NotI restriction sites. For Pax3sh, we replaced GFP with DsRed2, as described previously (Jacob et al., 2011).

To generate the HDAC2-overexpressing lentiviral construct and a GFP control construct, we first replaced the U6 promoter of pSiCoRGFP with the EF1 $\alpha$ promoter. pSiCoR-GFP was digested with XbaI, blunted, and redigested with NotI. pEF-ENTR A (plasmid 17427, Addgene; Campeau et al., 2009) was digested with NcoI, blunted, and redigested with NotI to excise the EF1 $\alpha$ promoter that was religated into digested pSiCoR-GFP. We then digested pSiCoR-GFP-EF1 $\alpha$ with BamHI and NotI and ligated in mouse HDAC2 cDNA generated by PCR using the HDAC2-overexpressing construct as a template. We called this construct pSiCoR-GFP-EF1 $\alpha$-HDAC2. PCR primers for HDAC2 were as follows: forward $5^{\prime}$-ccGGATCCATGGCGTACAGTCAAGGAGGC-3', reverse 5 '-ccGCGGCCGCTCAAGGGTTGCTGAGTTGTTC-3'. The pSiCoR-GFP-EF1 $\alpha$ construct was used as a control construct in experiments using $\mathrm{pSiCoR}-\mathrm{GFP}-\mathrm{EF} 1 \alpha$-HDAC2. To produce lentiviral parti- cles, we followed the recommendations of the ViraPower Lentiviral Expression Systems Manual (Invitrogen). JoMal cells were transduced at a multiplicity of infection of 2-5 and washed $48 \mathrm{~h}$ after transduction.

Cell culture. The JoMa1 neural crest cell-derived cell line was cultured and induced to differentiate into glia as described previously (Maurer et al., 2007) with modifications. JoMa1 cells were kept on plates that had been coated with poly-D-lysine ( $1 \mathrm{mg} / \mathrm{ml}$; Sigma-Aldrich) for $5 \mathrm{~min}$ and fibronectin $(1 \mathrm{mg} / \mathrm{ml})$ for $1 \mathrm{~min}$. Cells were maintained in DMEM/ Ham's F12 medium (1:1; Invitrogen) supplemented with: $1 \% \mathrm{~N}_{2}$ (Invitrogen), 2\% B27 (Invitrogen), 10 ng/ml EGF (Peprotech), 4 ng/ml FGF (Peprotech), $100 \mathrm{U} / \mathrm{ml}$ penicillin-streptomycin (Invitrogen), and 10\% chick embryo extract (both homemade and purchased from Seralab). Proliferation and undifferentiated state were maintained by adding 200 nM 4-hydroxytamoxifen (Sigma). For differentiation into glial cells, tamoxifen was withdrawn for $4 \mathrm{~h}$ before the addition of $5 \mu \mathrm{M}$ forskolin (Sigma) and $50 \mathrm{ng} / \mathrm{ml}$ heregulin- $\beta 1$ (Peprotech) and the cells were maintained in this medium for the indicated times mentioned in the figure legends (medium was replaced every second day).

Neural crest explants were obtained from E8.75 Naval Medical Research Institute mouse embryos. Neural tubes were isolated and plated to enable neural crest cells to migrate out for $12 \mathrm{~h}$, as described previously (Greenwood et al., 1999). Neural tubes were then removed and cells were switched to complete medium (Stemple and Anderson, 1992) containing $50 \mathrm{ng} / \mathrm{ml}$ heregulin- $\beta 1$ and $5 \mu \mathrm{M}$ forskolin to induce differentiation into glia. At this time, $0.6 \mu \mathrm{M}$ mocetinostat (an HDAC1/2specific inhibitor; Selleckchem) or its vehicle was also added and cells were incubated for $56 \mathrm{~h}$. This medium was replaced every day.

Generation of conditional knock-out mice. To ablate HDAC1 and HDAC2 in neural crest cells, mice homozygous for floxed Hdac1 and floxed Hdac2 alleles (RRID:MGI:4440556 and RRID:MGI:4440559, respectively; Yamaguchi et al., 2010) were crossed with mice expressing the Cre recombinase under control of the Wnt1 promoter (Wnt1-Cre; RRID:MGI:2386570; Danielian et al., 1998). For in vivo fate mapping, Wnt1-Cre;Hdacl floxed/wildtype;Hdac2 floxed/wild-type mice were crossed with $H d a c 1$ floxed/floxed; Hdac2 floxed/floxed;R26R-Lacz ${ }^{+/+}$mice in which the Lacz reporter gene has been inserted into the ROSA26 locus preceded by a floxed stop sequence (RRID:MGI:1861932; Soriano, 1999). Genotypes were determined by PCR on genomic DNA. Animal use was approved by the veterinary office of the Canton of Zürich, Switzerland.

Whole-mount $X$-Gal staining. Embryos harvested at different time points of gestation were fixed for $5-10 \mathrm{~min}$ in $4 \%$ PFA and $0.2 \%$ glutaraldehyde in PBS. After extensive washes in PBS, embryos were stained in $\mathrm{X}$-Gal staining solution containing the following: $5 \mathrm{~mm} \mathrm{~K}_{3} \mathrm{Fe}(\mathrm{CN})_{6}, 5 \mathrm{~mm}$ $\mathrm{K}_{4} \mathrm{Fe}(\mathrm{CN})_{6}, 2 \mathrm{~mm} \mathrm{MgCl}_{2}, 0.1 \%$ sodium deoxycholate, $0.02 \% \mathrm{NP}-40$, and $1 \mathrm{mg} / \mathrm{ml} \mathrm{X}$-Gal in PBS for 1 to several hours at $37^{\circ} \mathrm{C}$.

Immunofluorescence and in situ hybridization. Embryos were fixed for $1-4 \mathrm{~h}$ in $4 \%$ PFA, cryopreserved overnight in $30 \%$ sucrose, and embedded in optimal cutting temperature compound (Tissue-Tek). Cryosections $(10$ or $20 \mu \mathrm{m})$ were submitted to antigen retrieval in citrate buffer at $65^{\circ} \mathrm{C}$ for $2 \mathrm{~h}$ before the blocking step. Neural crest explants were fixed for $15 \mathrm{~min}$ at room temperature (RT) in 4\% PFA. Cryosections and neural crest explants were incubated in blocking buffer ( $10 \%$ goat serum, $0.3 \%$ Triton $\mathrm{X}-100,0.2 \%$ Tween 20 in PBS or $1 \%$ BSA, $0.3 \%$ Triton $\mathrm{X}-100,0.2 \%$ Tween 20 in PBS for primary goat antibodies) for $30 \mathrm{~min}$, and then with primary antibodies overnight at $4^{\circ} \mathrm{C}$. Secondary antibodies were applied for $1 \mathrm{~h}$ and DAPI for $5 \mathrm{~min}$ at RT.

The primary antibodies used were as follows: HDAC1 (1:1000, PA1860, rabbit polyclonal; Affinity Bio Reagents, RRID:AB_2118091), HDAC2 (1:200, H2663, mouse monoclonal; Sigma Aldrich, RRID: AB_261977), cleaved Caspase 3 (1:500, 9661, rabbit polyclonal; Cell Signaling Technology), Sox10 (1:200, N-20, sc-17342, goat polyclonal; Santa Cruz Biotechnology, RRID:AB_2195374; or 1:200, SI058C01, rabbit polyclonal; DCS, RRID:AB_2313583), Pax3 (1:100, mouse monoclonal; Developmental Studies Hybridoma Bank, RRID:AB_528426), NeuroD1 (1:200, sc-1084, goat polyclonal; Santa Cruz Biotechnology, RRID:AB_630922), and Islet1 (1:200, 39.4D5, mouse monoclonal; Developmental Studies Hybridoma Bank, RRID:AB_528173).

The secondary antibodies used were as follows: donkey anti-mouse Alexa Fluor 488 (1:500; Invitrogen, RRID:AB_141607), donkey anti- 
A
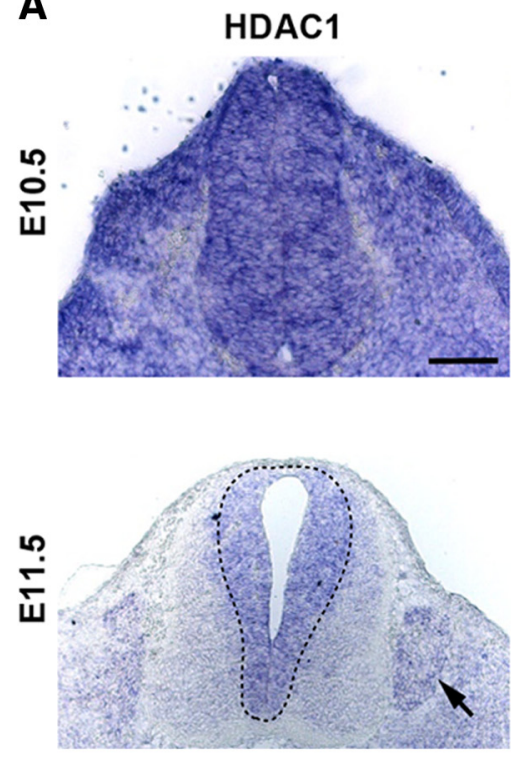
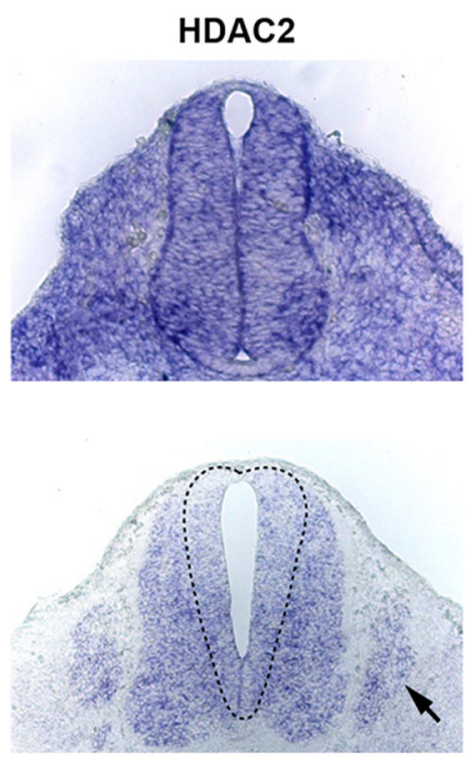

B
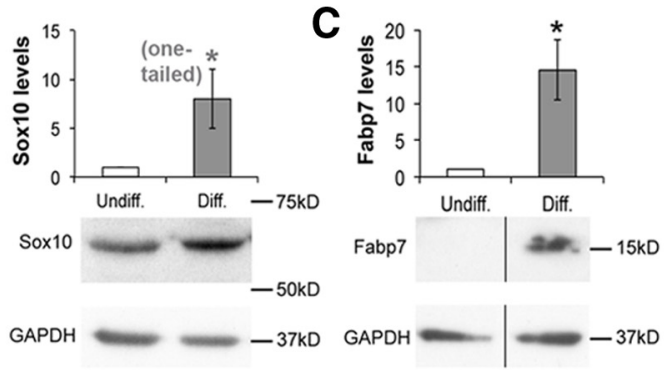

D

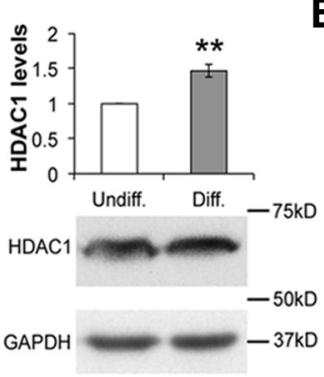

E

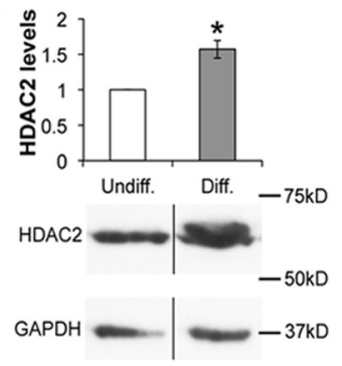

Figure 1. HDAC1/2 are robustly expressed in DRG and upregulated in JoMa1 neural crest cells during specification into glia. $A$, In situ hybridization of $H d a c 1$ and $H d a c 2$ on transverse neural tube sections of E10.5 and E11.5 wild-type mouse embryos (representative pictures of three embryos analyzed). Arrows indicate DRG. Scale bar, $100 \mu \mathrm{m}$. Western blot pictures of Sox10 (B), Fabp7 (C), HDAC1 (D), and HDAC2 $(\boldsymbol{E})$ and quantification normalized to GAPDH in $4 \mathrm{~d}$ differentiated (Diff.) versus undifferentiated (Undiff. $=1$ ) JoMa1 cells. Dividing lines indicate that samples have been loaded on the same gel, but not on consecutive lanes. $p$-values (two-tailed paired Student's t test unless stated otherwise in the figure): 0.0418 (B), $0.0157(\boldsymbol{C}), 0.0026$ (D), 0.011 (E). Results are from at least three independent experiments. Error bars indicate SEM.

rabbit Cy5 (1:200; Jackson ImmunoResearch, RRID:AB_2307444), donkey anti-rabbit Alexa Fluor 488 (1:500; Jackson ImmunoResearch, RRID: AB_2313584), and donkey anti-goat Cy3 (1:500; Jackson ImmunoResearch, RRID:AB_2307351).

Cells or sections were observed using a fluorescence microscope (Axioplan2 Imaging; Carl Zeiss) with $20 \times / 0.50$ numerical aperture (NA), $40 \times / 0.75 \mathrm{NA}$, or $63 \times / 1.25 \mathrm{NA}$ (oil-immersion) plan Neofluar objectives. Images were digitized with a PowerShot G5 camera (Canon) and acquired with AxioVision 4.5 software (Carl Zeiss). For confocal analyses, cells were observed using a Leica DMIRE2 inverse microscope and a Leica SP2 AOBS point laser scanning confocal. Optical sections were collected at $2.0 \mu \mathrm{m}$ intervals using Leica LCS software. Images were assembled and the brightness and contrast were adjusted using Adobe Photoshop CS5 12.0.4. Where indicated in the figure legends, $z$-series projections were generated using ImageJ $1.46 \mathrm{r}$ software (RRID:nif-0000-30467). Quantification analyses were done with CellProfiler 2.0 software (Broad Institute, RRID:nif-0000-00280).

In situ hybridization with digoxigenin-labeled riboprobes was performed on cryosections as described previously (Paratore et al., 1999). Hybridization signals were visualized with NBT/BCIP (Roche Diagnostics). Antisense riboprobes were labeled with digoxigenin according to the manufacturer's instructions (Roche Diagnostics).

Western blot and immunoprecipitation. Twenty-four hour differentiated for immunoprecipitations, IPs, or $4 \mathrm{~d}$ differentiated (for Western blot) or undifferentiated JoMal cells were lysed. IPs were performed as described previously (Jacob et al., 2011). Immunoprecipitating antibodies were cross-linked to Protein A/G PLUS Agarose beads (Santa Cruz Biotechnology) according to the online protocol of New England BioLabs. Proteins were eluted in $0.1 \mathrm{M}$ glycine, $\mathrm{pH} 2.5$, and $1 \mathrm{~m}$ Tris, $\mathrm{pH}$ 8.0, was added for neutralization. Lysates and IPs were submitted to SDSPAGE and analyzed by Western blotting.

The primary antibodies used were as follows: HDAC1 (1:2000, PA1860, rabbit polyclonal; Affinity BioReagents), HDAC2 (1:2000, H2663, mouse monoclonal; Sigma Aldrich), Sox10 (N-20, sc-17342, goat polyclonal, Santa Cruz Biotechnology, or mouse monoclonal, R\&D Systems, RRID:AB_2195180, both at 1:500), Pax3 (1:1000, mouse monoclonal; Developmental Studies Hybridoma Bank), Fabp7 (1:500, rabbit polyclonal; Abcam, RRID:AB_880078), GAPDH (1:5000, mouse monoclonal; Hytest, RRID:AB_1616722). All secondary antibodies were from
Jackson ImmunoResearch: goat anti-mouse HRP (RRID:AB_2313585), goat anti-rabbit HRP (RRID:AB_2313586), and donkey anti-goat HRP (RRID:AB_2313587). Two micrograms of antibody were used per IP.

Luciferase gene reporter assay. JoMa1 cells were transfected in undifferentiated or differentiating conditions. For HDAC1/2 inhibition, cells were first incubated with $0.6 \mu \mathrm{M}$ Mocetinostat (Selleckchem) for $48 \mathrm{~h}$ in undifferentiated conditions before transfection and induction of differentiation. Luciferase activity was first normalized to a luciferase-empty control (transfected with the overexpressing construct at the same ratio Fugene 6:DNA), and then normalized to $\beta$-galactosidase activity (assay according to the instructions of Promega). Results are expressed as percentage of the control.

For transfection, Fugene 6 (Roche) was used at a 3:1 ratio Fugene 6:DNA, according to the manufacturer's recommendations with the following modification: the DNA was incubated in Optimem for 5 min at room temperature before addition of Fugene 6. The mix Fugene 6:DNA was then incubated for $25 \mathrm{~min}$ at room temperature before being added to cells. Cells were lysed in $110 \mu \mathrm{l}$ of reporter lysis buffer (Promega) and assayed for luciferase activity. Forty microliters of lysate were subjected to two consecutive injections of $25 \mu \mathrm{l}$ of luciferase substrate and values were recorded after an integration time of 30 s. Efficiency of transfection was evaluated by measuring $\beta$-galactosidase activity of a cotransfected lacZ construct (Promega). Beta-galactosidase activity assay was as follows: $50 \mu \mathrm{l}$ of assay buffer $2 \times$ was added to $50 \mu \mathrm{l}$ of lysate and $\beta$-galactosidase activity was recorded after a $15-20 \mathrm{~min}$ incubation time at $37^{\circ} \mathrm{C}$. Endogenous $\beta$-galactosidase activity (as determined from cells transfected only with overexpressing or shRNA constructs at the same ratio Fugene 6:DNA) was subtracted.

We have verified that no significant change of luciferase activity of the empty luciferase construct pGL3 (backbone construct; Promega) occurred when overexpressing or shRNA constructs were transfected. Cells were cotransfected with $0.8 \mu \mathrm{g}$ of luciferase construct (Sox10 MCS4, Sox10 MCS1C, P0 promoter, Pax3 promoter, Fabp7 promoter); $0.8 \mu \mathrm{g}$ of GFP-, HDAC1-, or HDAC2-overexpressing construct; or between 0.05 and $0.8 \mu \mathrm{g}$ of Sox 10- or Pax3-overexpressing construct, $0.8 \mu \mathrm{g}$ of shRNA construct (control shRNA, HDAC1 shRNA, HDAC2 shRNA, Pax3 shRNA, Sox10 shRNAs), and $300 \mathrm{ng}$ of lacZ construct. 
A

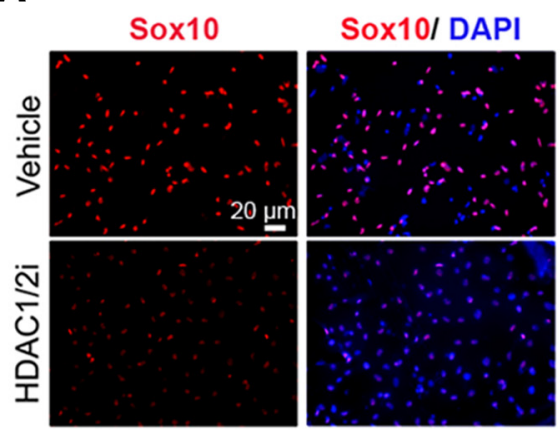

C

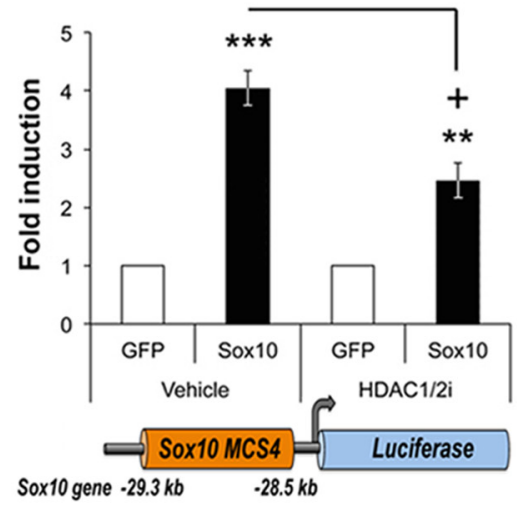

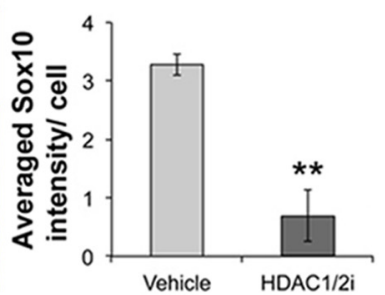

B

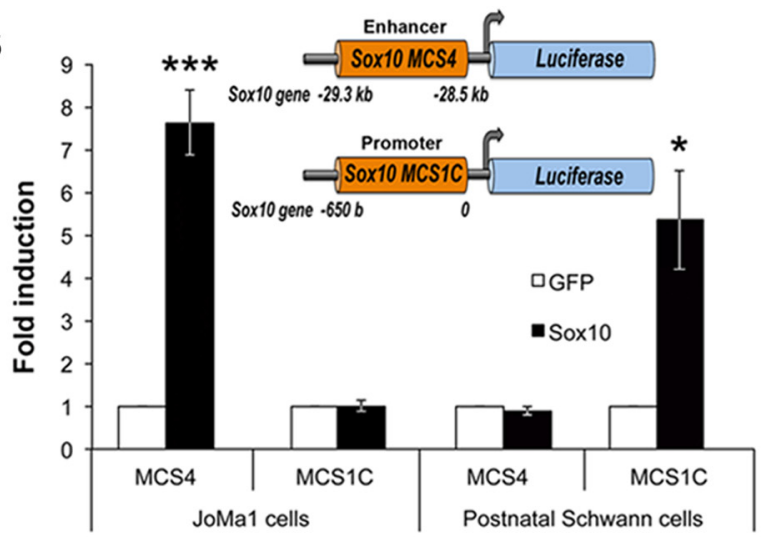

E
P0 promoter

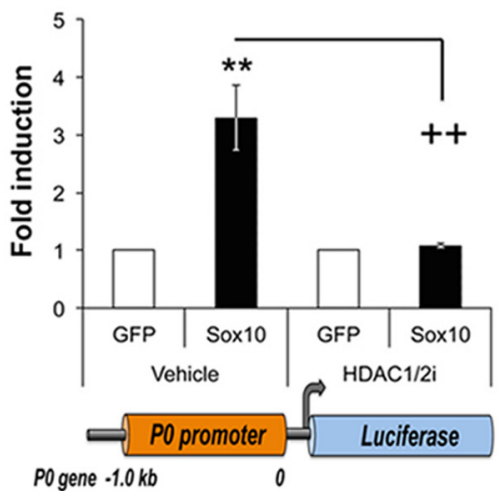

Figure 2. HDAC1/2 activity is required to maintain high Sox10 levels and for Sox10-dependent activation of Sox10, Fabp7 and P0 gene regulatory regions during specification into glia. $A$, Immunofluorescence of Sox 10 (red; DAPI = nuclei in blue) on mouse neural crest explants in differentiating conditions with or without the HDAC1/2 inhibitor mocetinostat (HDAC1/2i; $0.6 \mu \mathrm{m}$ ), and quantification of Sox10 (200 cells per explant, 3 explants per condition, $n=3$ ). Relative luciferase activity of Sox10 MCS4 (B,C), Sox10 MCS1C (= Sox10 promoter region, $\boldsymbol{B})$, Fabp7 promoter (D), and $P$ O promoter $(\boldsymbol{E})$-driven luciferase reporter constructs (-luc) induced by Sox10 overexpression compared with GFP $(=1)$ with or without HDAC1/2i $(\boldsymbol{C}-\boldsymbol{E}) 24 \mathrm{~h}$ after transfection and induction of differentiation in postnatal primary rat Schwann cells $(\boldsymbol{B})$ or in JoMa1 cells $(\boldsymbol{B}-\boldsymbol{E})$. p-values from two-tailed unpaired $(\boldsymbol{A})$ or paired $(\boldsymbol{B}-\boldsymbol{E})$ Student's $t$ test: $0.0063(\boldsymbol{A}) ;{ }^{*} 0.0193,{ }^{* * *} 6.91462 \mathrm{E}-06(\boldsymbol{B})$; ${ }^{* *} 0.0029,{ }^{* * *} 0.0001,+0.026(\boldsymbol{C}) ;{ }^{* *} 1.00025 \mathrm{E}-05,{ }^{* *} 0.0001,+0.017(\boldsymbol{D}) ;$ and ${ }^{* *} 0.0041,++0.028(\boldsymbol{E})$. Results are from at least three independent experiments. Error bars indicate SEM.

Quantitative real-time PCR. Isolation of RNA was performed using TRIzol reagent (Invitrogen) according to the manufacturer's recommendations. cDNA was produced using SuperScript III Reverse Transcriptase (Invitrogen). Quantitative real-time PCR (qRT-PCR) analyses were performed on an ABI 7000 Sequence Detection System (Applied Biosystems) using $2 \times$ SYBR Green PCR Mastermix (Applied Biosystems) according to the manufacturer's recommendations.

Primer sequences were as follows: for P0, forward 5' -CCCTGGCCATTGTGGTTTAC-3', reverse 5'-CCATTCACTGGACCAGAAGGAG-3'; for GAPDH, forward 5' -CGTCCCGTAGACAAAATGGT-3', reverse 5' TTGATGGCAACAATCTCCAC- $3^{\prime}$. The amplification program was as follows: $5 \mathrm{~min}$ at $96^{\circ} \mathrm{C} ; 40$ steps of $30 \mathrm{~s}$ at $96^{\circ} \mathrm{C}, 30 \mathrm{~s}$ at $60^{\circ} \mathrm{C}, 30 \mathrm{~s}$ at $72^{\circ} \mathrm{C}$, and $5 \mathrm{~min}$ at $72^{\circ} \mathrm{C}$.

ChIP. Experiments with JoMal neural crest cells were performed as described previously (Jacob et al., 2011). Two micrograms of antibodies were used per IP.

The primer sequences for SYBR Green qRT-PCR were as follows: Sox10 MCS4, forward 5'-AACGAGGGATGCAAGGAAGG-3', reverse 5'-GGGAACAATGTCAACGTCGC-3'; Pax3 promoter, forward 5' TCCACAGGTGAAAAGCAGGG-3' ${ }^{\prime}$, reverse $5^{\prime}$-GGTGTCCCTGTCCCTCTACA-3'; P0 promoter, forward 5'-CCCCCTACCCTAGGTT GGAA-3', reverse 5'-CCTTTGCCATGGCCTTTTGG-3'; Fabp7 promoter, forward $5^{\prime}$-AGTTTTCTGTTCCCAGGCCC-3', reverse 5' TGGGTTAGCGGAGTAGGTCA-3'; Sox10 MCS1C, forward 5' GGCAATGGTTTAGGGTCCCA-3', reverse 5'-TTGGCATCTGGTG TGAGCAT- $3^{\prime}$; control sequence (localized at $-2.3 \mathrm{~kb}$ from transcription start site of P0 gene), forward 5' -ATCCAAAGCCAAAAAGAAAAGTGC$3^{\prime}$, reverse 5'-GTACGGGTACTTACAACAAATGGC-3'.
The antibodies used were as follows: mouse anti-HDAC2 (H2663; Sigma Aldrich), rabbit anti-HDAC1 (PA1-860; Affinity BioReagents), goat anti-Sox10 (N-20, sc-17342; Santa Cruz Biotechnology), mouse anti-Pax3 (Developmental Studies Hybridoma Bank), mouse anti-HH3 (positive control; Millipore, RRID:AB_309763), or rabbit anti-mouse IgG (negative control; Sigma, RRID:AB_260634).

\section{Results}

HDAC1 and HDAC2 are robustly expressed during specification of neural crest cells into peripheral glia We found that HDAC1 and HDAC2 were widely expressed in the neural tube and surrounding tissue at E10.5 in developing mouse embryos (Fig. 1A). At E11.5, however, HDAC1/2 expression was concentrated in the neural tube and in DRG (Fig. $1 A$ ) and remained highly expressed in these structures and in peripheral nerves at E12.5 and E14.5 (data not shown). Specification of neural crest cells into peripheral glia occurs at E11 (Jessen and Mirsky, 2005). Because HDAC1/2 expression was maintained during this process in DRG, we investigated the potential involvement of HDAC1/2 in the transcriptional control of peripheral glia specification. We initially used the neural crest cell-derived line JoMa1, which differentiates into glia upon treatment with the neuregulin 1 isoform heregulin-betal (Maurer et al., 2007). Within $4 \mathrm{~d}$, heregulin-beta1 upregulated Sox10 (Fig. $1 B$ ) and the early glial marker Fabp7 (Fig. 1C) and led to a mild but significant upregulation of HDAC1 (Fig. 1D) and HDAC2 (Fig. 1E) in these cells. 
A

P0 promoter, $24 \mathrm{~h}$

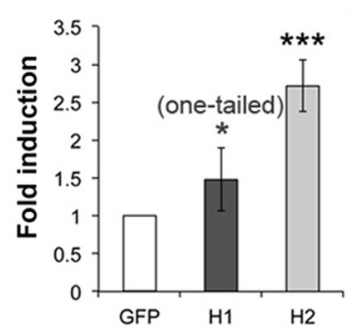

D

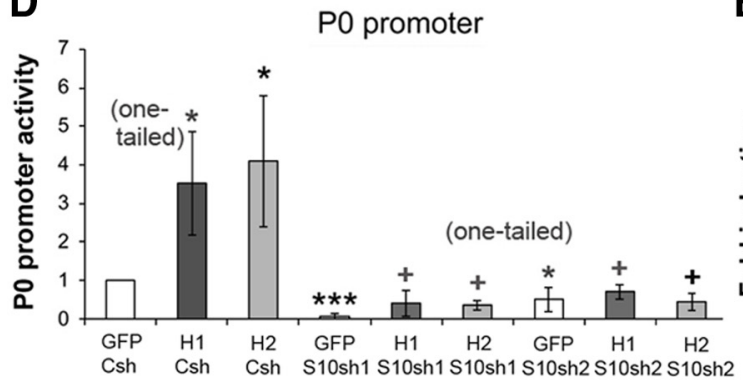

PO mRNA

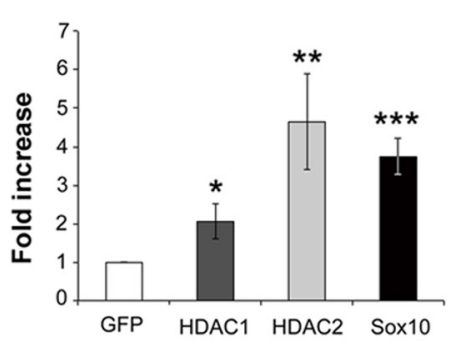

E

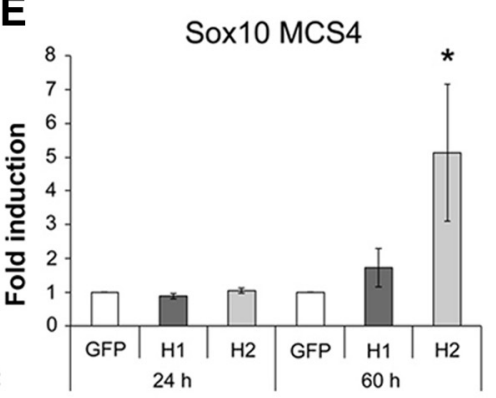

C

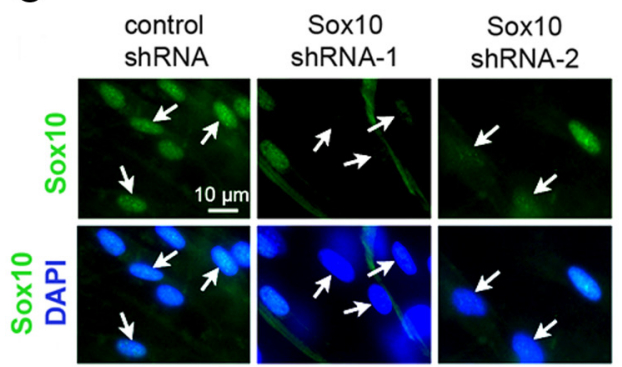

F

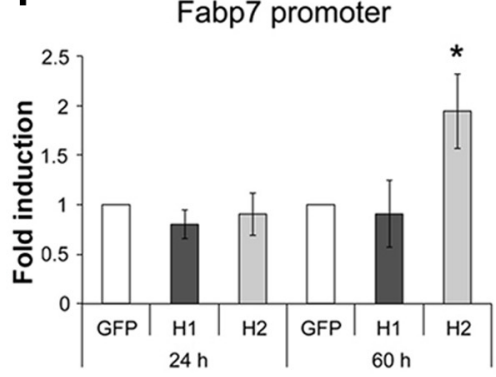

G

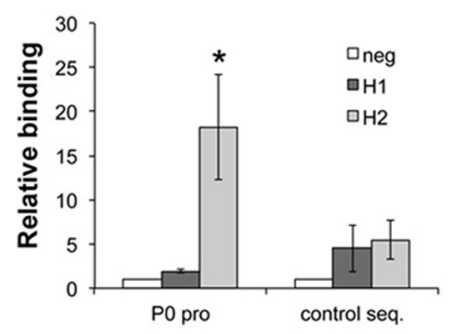

H

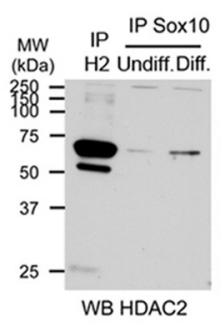

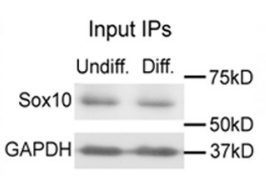

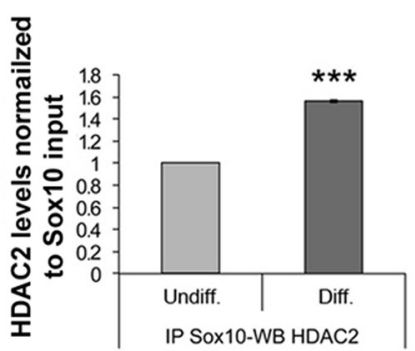

Figure 3. HDAC2 binds to and activates the PO promoter, whereas HDAC2-dependent activation of Sox 10 MCS4 and the Fabp7 promoter is most likely indirect. Relative luciferase activity of $P O$ promoter-luc $(\boldsymbol{A}, \boldsymbol{D})$, Sox10 MCS4-luc $(\boldsymbol{E})$, and Fabp7 promoter-luc $(\boldsymbol{F})$ by HDAC1 (H1) or HDAC2 (H2) overexpression with or without Sox10 shRNAs (S10sh; $\boldsymbol{D}$ ) or in the presence of Sox10 shRNAs alone (D) compared with GFP $(=1)$ or GFP/Control shRNA (GFP/CSh $=1), 24 \mathrm{~h}(\boldsymbol{A})$ or 24 and $60 \mathrm{~h}(\boldsymbol{E}, \boldsymbol{F})$ after transfection and induction of differentiation or $72 \mathrm{~h}(\boldsymbol{D})$ after transfection and $24 \mathrm{~h}$ in differentiating conditions. $\boldsymbol{B}$, Fold increase of PO mRNA induced by HDAC1, HDAC2, or Sox10 overexpression compared with GFP $(=1)$ and normalized to GAPDH mRNA $48 \mathrm{~h}$ after transfection and induction of differentiation. C, Immunofluorescence of Sox10 (green) and DAPI (blue = nuclei) labeling of mouse DRG explant cultures $3 \mathrm{~d}$ after transfection with control shRNA, Sox 10 shRNA-1, and Sox10 shRNA-2 constructs. G, ChIP of HDAC1 (H1) and HDAC2 (H2) to PO promoter (PO pro) or control sequence (control seq.) compared with negative control (IgG $=$ neg $=1$ ). $\boldsymbol{H}$, Immunoprecipitation of HDAC2 or Sox10 in undifferentiated or $24 \mathrm{~h}$ differentiated JoMa1 cells and Western blot for HDAC2. Quantification of coimmunoprecipitated HDAC2 normalized to Sox 10 input. $p$-values (two-tailed paired Student's $t$ test, unless stated otherwise): ${ }^{*} 0.041$ and ${ }^{* * *} 0.00046(\boldsymbol{A}) ;{ }^{*} 0.042,{ }^{* *} 0.0058,{ }^{* * *} 8.4726 \mathrm{E}-05(\boldsymbol{B}) ;{ }^{*} 0.037,0.041,0.03,{ }^{* * *} 0.00004(\boldsymbol{D}, p$-values compared with the control GFP/(Sh), + 0.044, 0.031, 0.029,0.029 (D, $p$-values compared with H1/Csh for H1/S10sh or H2/(SSh for H2/S10sh); $0.044(\boldsymbol{E}) ; 0.03(\boldsymbol{F}) ; 0.044(\boldsymbol{G})$; and ${ }^{* * *} 0.0007(\boldsymbol{H})$. Results are from at least three independent experiments. Error bars indicate SEM.

Interestingly, a second HDAC2 band of slightly higher molecular weight appeared in glia-differentiated JoMal cells, indicating posttranslational modification of HDAC2 during this process. Together, these data confirmed that the JoMal neural crest cell line can be specified into glia upon heregulin-betal treatment and was therefore suitable for our study. In addition, the robust expression of HDAC1/2 concomitant with Sox10 upregulation prompted us to seek a potential involvement of $\mathrm{HDAC} 1 / 2$ in the regulation of peripheral glia specification.

\section{HDAC1/2 activity is required to maintain high Sox10} expression and for Sox10-dependent activation of Sox10, $F a b p 7$, and $P O$ gene regulatory regions during specification into glia

Precise regulation of Sox 10 expression is critical for specification of neural crest cells into glia (Paratore et al., 2001). To determine whether HDAC1/2 activity is involved in the control of Sox 10 expression during this process, we chose to use mouse neural crest explants because the myc-immortalized JoMa1 cell line may not completely mirror all transcriptional regulations that occur in normal neural crest. We induced glia specification in mouse neural crest explants in the presence of the HDAC1/2-specific inhibitor mocetinostat $(0.6 \mu \mathrm{M})$ and analyzed Sox10 levels. At this concentration, mocetinostat is a specific inhibitor of $\mathrm{HDAC} 1 / 2\left(\mathrm{IC}_{50}\right.$ for HDAC1 $=0.15 \mu \mathrm{M}, \mathrm{IC}_{50}$ for HDAC2 $=0.29$ $\mu \mathrm{M})$. It also becomes active on HDAC3 at higher concentrations $\left(\mathrm{IC}_{50}\right.$ for $\left.\mathrm{HDAC} 3=1.66 \mu \mathrm{M}\right)$. Inhibition of $\mathrm{HDAC} 1 / 2$ activity strongly decreased Sox10 expression (Fig. 2A) without a significant increase in cell death (data not shown), indicating that HDAC1 and/or HDAC2 is necessary to maintain high Sox10 expression during specification of neural crest cells into glia.

To determine the underlying molecular mechanism, we started from the fact that Sox 10 upregulates its expression by binding and activating its own promoter and $5^{\prime}$ enhancers (Werner et al., 2007; Antonellis et al., 2008). Activation of the Sox10 
A
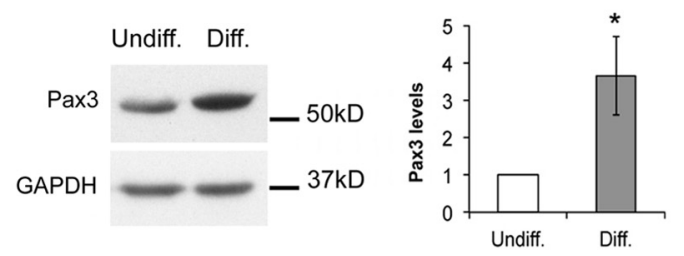

B

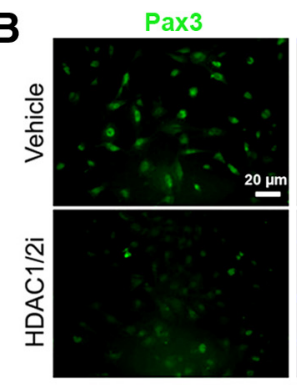

E
C
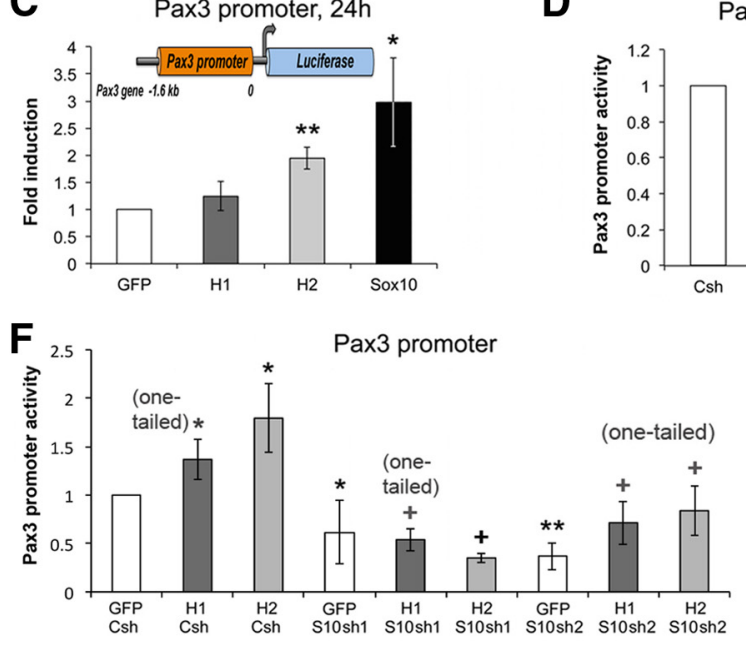

D

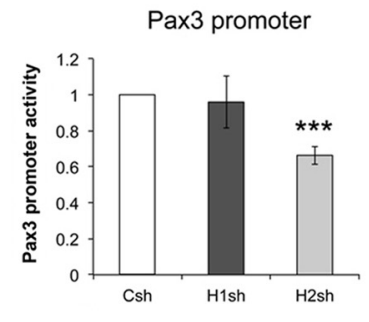

G

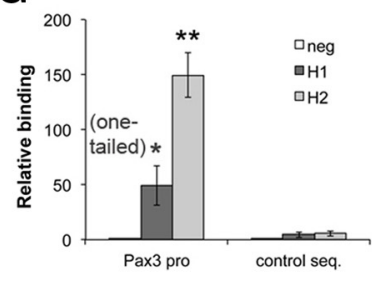

Pax3/ DAPI
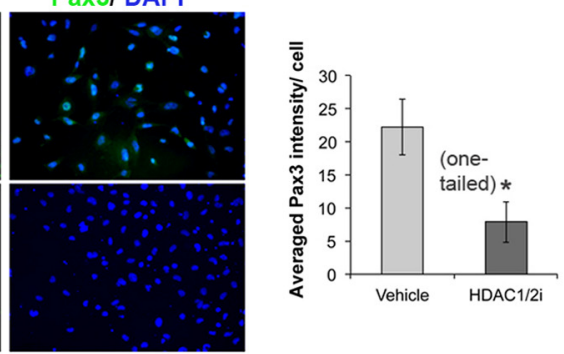

Figure 4. HDAC2 controls Pax3 expression in neural crest cells. $A$, Western blot of Pax3 and quantification normalized to GAPDH in $4 \mathrm{~d}$ differentiated (Diff.) compared with undifferentiated (Undiff. $=1$ ) JoMa1 cells. $\boldsymbol{B}$, Immunofluorescence of Pax3 (green; DAPI = nuclei in blue) in neural crest explants in differentiating conditions with or without the HDAC1/2 inhibitor mocetinostat (HDAC1/2i, $0.6 \mu \mathrm{m}$ ) and quantification of Pax3 ( $\sim 200$ cells per explant, 3 explants per condition, $n=3$ ). Relative luciferase activity of Pax3 promoter-luc upon HDAC1 (H1), HDAC2 (H2) or Sox10 overexpression (C) with or without Sox10 shRNAs (S10sh) or in the presence of Sox10 shRNAs alone $(\boldsymbol{F})$ compared with GFP $(=1)$ or GFP/control shRNA (GFP/Csh $=1$ ) 24 or $72 \mathrm{~h}$ (shRNA) after transfection and $24 \mathrm{~h}$ of induction of differentiation or in the presence of $\mathrm{H} 1 \mathrm{shRNA}(\mathrm{sh})$ or $\mathrm{H} 2 \mathrm{sh}$ compared with $\mathrm{Csh}(=1)(\boldsymbol{D}) 72 \mathrm{~h}$ after transfection and $24 \mathrm{~h}$ in differentiating conditions. $\boldsymbol{E}$, Western blot of HDAC2, Pax3, and GAPDH in JoMa1 cells expressing endogenous HDAC2 (C, control) or overexpressing HDAC2 (H20). A lentiviral vector was used to overexpress HDAC2. Control cells were transduced with a lentiviral vector expressing GFP. Cells were collected $72 \mathrm{~h}$ after transduction and induction of differentiation. Dividing lines indicate that samples have been loaded on the same gel, but not on consecutive lanes. G, ChIP showing relative binding of anti-HDAC1 (H1) and anti-HDAC2 (H2) antibodies to Pax3 promoter (Pax3 pro) or control sequence (control seq.) compared with negative control (lgG = neg = 1). H, ChIP showing relative binding of anti-Sox10 antibody to Sox10 MCS4, Sox10 MCS1C, Pax3 promoter (pro), Fabp7 pro, or control sequence region (control seq.) compared with negative control $(\lg G=$ neg $=1), 24 \mathrm{~h}$ after induction of differentiation. $p$-values from Student's $t$ test (two-tailed paired in $\boldsymbol{A}, \boldsymbol{C}, \boldsymbol{D}, \boldsymbol{E}-\boldsymbol{H}$ or unpaired in $\boldsymbol{B})$ unless stated otherwise: $0.044(\boldsymbol{A})$; $0.025(\boldsymbol{B}) ;{ }^{*} 0.041,{ }^{* *} 0.0016(\boldsymbol{C}) ; 0.0003(\boldsymbol{D}) ; 0.04(\boldsymbol{E}) ;{ }^{*} 0.047,0.031,0.048,{ }^{* *} 0.0032(\boldsymbol{F}, p$-values compared with control GFP/Csh), +0.026, 0.04, 0.028, 0.027 (F, $p$-values compared with H1/Csh for H1/S10 sh or to H2/Csh for H2/S10sh); ${ }^{*} 0.027$ and ${ }^{* *} 0.0019$ (G); 0.033 (one-tailed) and 0.0125 (two-tailed; $\boldsymbol{H}$ ). Results are from at least three independent experiments. Error bars indicate SEM.

MCS4 enhancer (also called U3) by Sox10 is critical for Sox10 expression in neural crest cells (Wahlbuhl et al., 2012). First, we used the luciferase gene reporter assay to test the activity of the Sox10 MCS4 enhancer and of Sox10 MCS1C (Sox10 promoter) in JoMal cells and postnatal primary Schwann cells upon Sox10 overexpression (Fig. 2B,C). Sox10 MCS4 was strongly activated in JoMa1 cells, whereas Sox10 MCS1C was not. In contrast, Sox10 MCS4 was not activated in postnatal Schwann cells, whereas Sox10 MCS1C was (Fig. 2B). These findings confirm the findings of Werner et al. (2007) and extend the importance of these two regulatory regions at different stages of development. Sox10 overexpression also robustly activated the promoters of the early determinants of Schwann cells, Fabp7 (Fig. 2D) and P0 (Fig. 2E), in JoMal cells.

Exogenous DNA transiently applied in cells is present in nucleosomal DNA at approximately the same levels as endogenous DNA (Zhang et al., 2002). We therefore tested the effects of HDAC1/2 inhibition in these validated settings. Inhibition of HDAC1/2 activity decreased Sox10-induced activation of Sox10 MCS4 (Fig. 2C), the Fabp7 promoter (Fig. 2D), and the P0 promoter (Fig. 2E). Therefore, HDAC1 and/or HDAC2 are needed for Sox10-dependent activation of these regulatory elements.
$P 0$ is a direct target gene of HDAC2, whereas HDAC2dependent activation of Sox 10 MCS4 and the Fabp 7 promoter is most likely indirect

In JoMal cells cultured in differentiating conditions, overexpression of HDAC2 and, to a lesser extent, of HDAC1 increased the activation of the $P 0$ promoter, as detected by luciferase gene reporter assay $24 \mathrm{~h}$ after transfection (Fig. $3 A$ ), and increased the transcript levels of P0 $48 \mathrm{~h}$ after transfection (Fig. $3 B$ ). To bind DNA, HDACs need to interact with a DNA-binding protein. Because Sox10 binds and activates the $P 0$ promoter (Peirano and Wegner, 2000; Peirano et al., 2000; Fig. 2E) and increases P0 transcript levels (Fig. $3 B$ ), we tested whether HDAC1/2-induced activation of the $P 0$ promoter requires Sox 10 by downregulating Sox10 with specific shRNAs (Fig. 3C). Indeed, this activation was suppressed when Sox10 was downregulated (Fig. 3D), indicating that HDAC1/2-mediated activation of the $P 0$ promoter is Sox 10 dependent.

HDAC2 activated Sox10 MCS4 and the Fabp7 promoter $60 \mathrm{~h}$ after transfection (Fig. 3E,F), but not after 24 h, suggesting an indirect activation mechanism. In contrast, the $P O$ promoter is likely to be activated in a direct manner. Indeed, using ChIP, we found HDAC2 bound to the $P 0$ promoter $24 \mathrm{~h}$ after induction of 
differentiation in JoMal cells (Fig. $3 G$ ). We previously showed that HDAC1/2 interact with Sox10 upon induction of differentiation in postnatal Schwann cells to activate the Sox 10 promoter and the Krox20 myelinating Schwann cell element (Krox20 MSE; Jacob et al., 2011). In JoMa1 cells also, Sox10 coimmunoprecipitated with HDAC2 and this interaction was significantly increased $24 \mathrm{~h}$ after induction of specification into peripheral glia (Fig. $3 H$ ). Together, these data indicate that HDAC2 interaction with Sox10 in neural crest cells increases upon induction of specification into glia to bind and activate the $P 0$ promoter.

\section{Pax3 is a direct target gene of HDAC2 in neural crest cells}

To understand how HDAC2 controls the activation of Sox10 MSC4 and the Fabp7 promoter, we looked for an intermediate HDAC target gene. In JoMal cells, Pax3 was upregulated upon differentiation into glia (Fig. 4A), which is consistent with functional roles in this process. To test whether HDAC1/2 are involved in controlling Pax3 expression, we used mouse neural crest explants cultured in gliadifferentiation conditions. We found that Pax 3 expression was decreased by HDAC1/2 inhibition (Fig. 4B), indicating that HDAC1 and/or HDAC2 is indeed involved in controlling Pax3 expression.

Overexpression of HDAC2 or Sox 10 in JoMa1 cells rapidly (24 h after transfection) activated the Pax3 promoter (Fig. 4C), whereas downregulation of HDAC2 by shRNA resulted in decreased activity (Fig. 4D). Consistently, HDAC2 overexpression resulted in increased Pax3 expression levels (Fig. 4E). Because HDAC2 interacted with Sox10 in JoMa1 cells (Fig. $3 \mathrm{H}$ ) and both HDAC2 and Sox 10 overexpression activated the Pax3 promoter (Fig. 4C), we tested whether Sox10 is involved in HDAC2mediated activation of the Pax3 promoter. HDAC2-induced activation of the Pax3 promoter was abolished when Sox10 was downregulated by shRNAs (Fig. $4 F$ ), showing that this activation is Sox10 dependent. Furthermore, we found that HDAC1 and HDAC2 were highly enriched at the Pax3 promoter (Fig. 4G). Sox 10 was also bound to the Pax3 promoter, but not to Sox10 MCS1C or the Fabp7 promoter (Fig. 4H). Consistent with previous studies (Werner et al., 2007; Antonellis et al., 2008; Wahlbuhl et al., 2012), Sox10 was bound to Sox10 MSC4 (Fig. 4H). These data strongly suggest that HDAC1/2 are recruited by Sox 10 to the Pax3 promoter. We conclude that Sox10 and HDAC2 control Pax3 expression in neural crest cells directly by binding and activating the $\operatorname{Pax} 3$ promoter.

\section{Pax3 is necessary for HDAC2-dependent activation of Sox10 MCS4 and for expression of early determinants of peripheral glia during specification}

We next hypothesized that Pax3 could be the critical HDAC2 intermediate target gene required for the maintenance of high Sox10 expression during specification of neural crest cells into glia. To test this hypothesis, we generated a lentiviral vector that carries a specific Pax3 shRNA to downregulate Pax3 in neural crest cells. Pax3 downregulation in JoMa1 cells resulted in significantly reduced Sox 10 and Fabp7 expression (Fig. 5A), indicating that Pax3 is necessary for Sox 10 and Fabp7 expression in neural crest cells.

Consistent with previous data (Wahlbuhl et al., 2012), mild Pax3 overexpression activated Sox10 MCS4 in JoMal cells, whereas high overexpression did not (Fig. 5B). In contrast, Sox 10 MCS4 activation increased with the amount of overexpressed Sox10 (Fig. 5B). Pax3-binding sites on Sox10 MCS4 are adjacent to Sox10-binding sites (Wahlbuhl et al., 2012). Therefore, high levels of Pax3 may limit the access of Sox10 to its own binding sites and prevent Sox10-induced activation of Sox10 MCS4. In addition, Sox10 and Pax3 can interact (Lang and Epstein, 2003), so an excess of Pax 3 could sequester Sox 10 away from its target genes. Because low levels of Pax3 activated Sox10 MCS4 (Fig. 5B), residual Pax3 expression in the presence of shRNA is likely to be sufficient to maintain Sox10 at moderate levels (Fig. 5A).

Pax3 downregulation reduced Sox10 MCS4 activation and prevented HDAC2-induced Sox10 MCS4 activation (Fig. 5C). Pax 3 also rapidly activated the $P 0$ promoter $24 \mathrm{~h}$ after transfection and induction of differentiation (Fig. 5D), but not the Fabp7 promoter (data not shown). Pax3 is known to bind Sox10 MCS4 (Wahlbuhl et al., 2012). We confirmed this binding in JoMa1 cells and found Pax3 to be additionally enriched at the PO promoter, but not at the Sox10 MCS1C (Fig. 5E). These data indicate that Pax3 is required for HDAC2-dependent maintenance of high Sox10 levels and expression of peripheral glia proteins during specification of neural crest cells into glia.

In vivo, HDAC1/2 are essential in neural crest cells for Pax 3 expression, maintenance of high Sox10 levels, and specification into peripheral glia

Next, we wanted to validate the relevance of HDAC1/2 functions in peripheral glia specification in vivo. Although HDAC1 and 
A
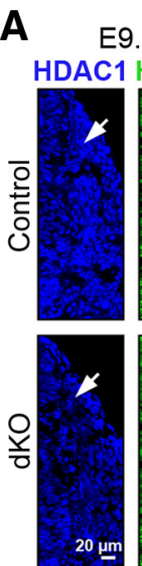

5
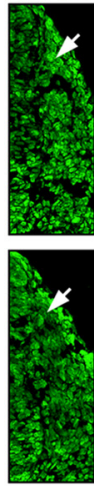

B

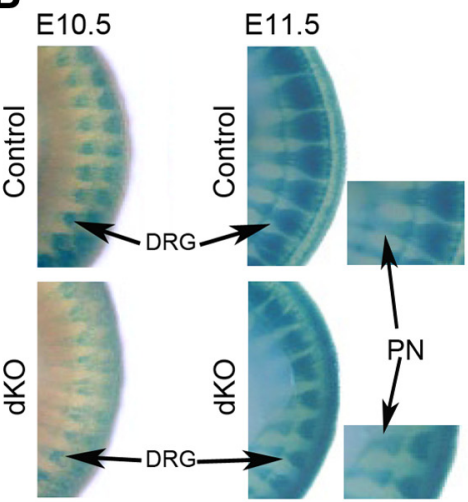

E

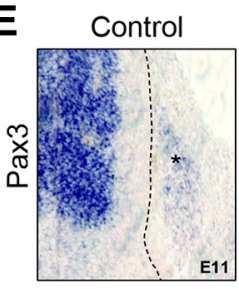

E10
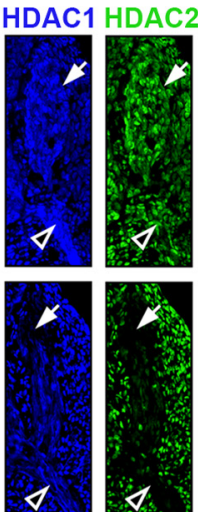

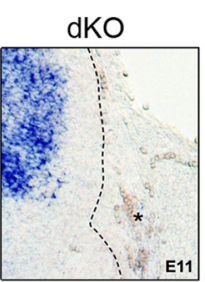

C
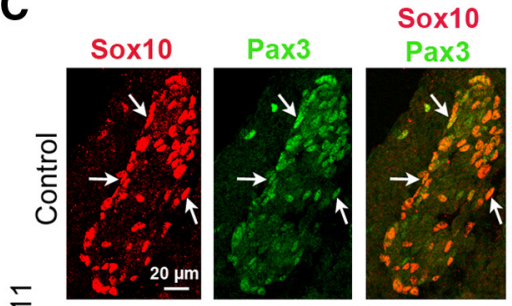

$\bar{\amalg}$
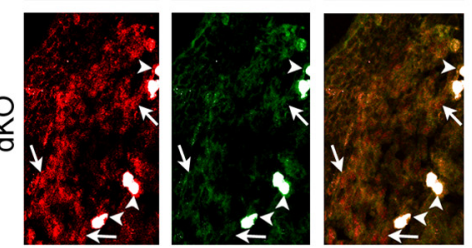

D
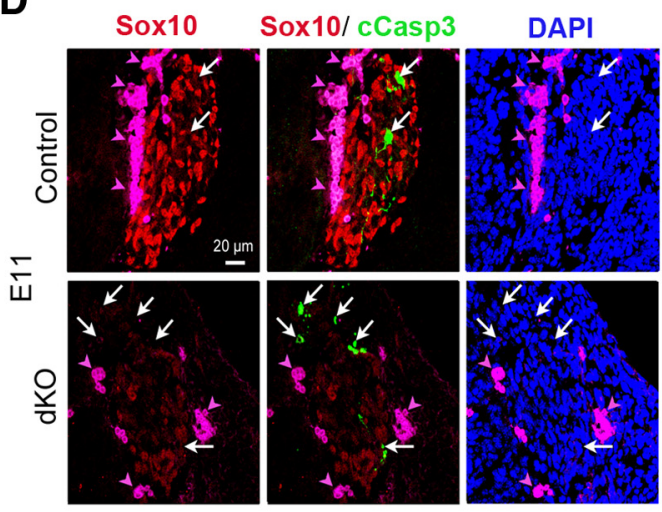

F
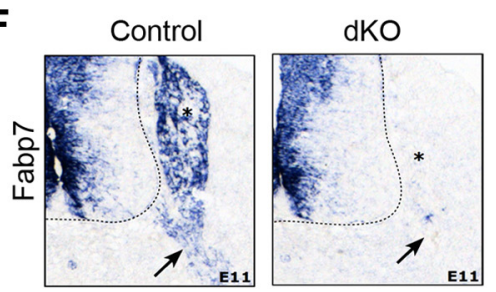
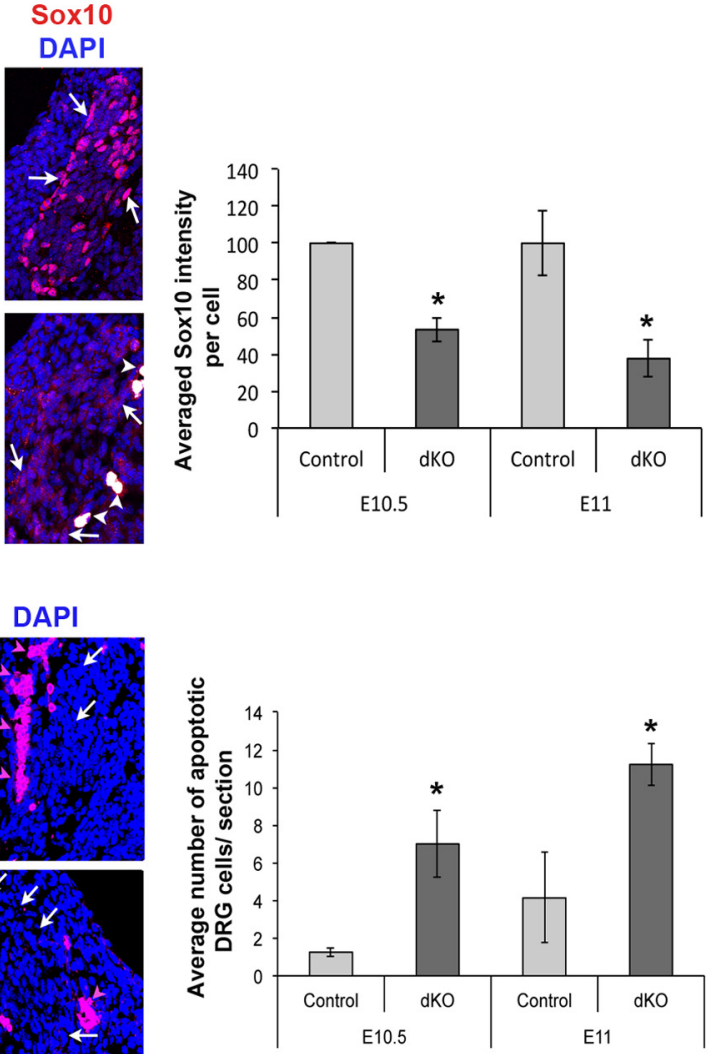

G
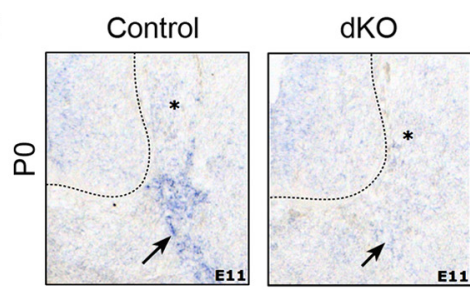

Figure 6. HDAC1/2 are essential for in vivo specification of peripheral glia. $A$, Coimmunofluorescence of HDAC1 (blue) and HDAC2 (green) in E9.5 and E10 dKO DRG and peripheral nerves. White arrows indicate DRG and arrowheads peripheral nerves. Three control and three dKO embryos for each age were stained and representative photographs are shown. $\boldsymbol{B}$, Whole-mount in vivo fate mapping using the recombination-dependent Rosa26-lacZ reporter allele at E10.5 and E11.5. Spinal cords imaged at the same level in control and dK0 embryos are shown. Insets on the right are a magnification of two E11.5 DRG and their peripheral nerve (PN). Arrows show DRG or PN, as indicated in the figure. C, Confocal pictures (z-series projections) of Sox10 (red) and Pax3 (green) coimmunofluorescence and DAPI labeling (= nuclei in blue) in E11 control and HDAC1/2 dKO DRG, and Sox10 quantification at E10.5 and E11 (Sox10-expressing cells in DRG of 3 controls and $3 \mathrm{dKOs}$ for each developmental stage). Overlay of Sox10 and Pax3 appears yellow, and of Sox10 and DAPI appears pink. Arrows indicate some Sox10-expressing cells, arrowheads some nonspecific auto-fluorescence (white). D, Confocal pictures of Sox10 (red) and cleaved Caspase 3 (cCasp3, green) coimmunofluorescence and DAPI labeling (blue) in E11 control and HDAC1/2 dKO DRG, and quantification of apoptotic cells (cCasp3-positive) in DRG at E10.5 and E11 (3 controls and $3 \mathrm{dKO}$ s for each developmental stage). White arrows show cCasp3-positive cells, pink arrowheads show nonspecific auto-fluorescence (magenta). In situ hybridization of $\operatorname{Pax} 3(\boldsymbol{E}), F a b p 7(\boldsymbol{F})$, and $P O(\boldsymbol{G})$ in E11 controls and dKOs (representative pictures of 3 controls and $3 \mathrm{dKO}$ s). Asterisks indicate DRG, arrows, peripheral nerves. p-value from two-tailed paired $\left(\boldsymbol{C}\right.$, E10.5) or unpaired $(\boldsymbol{C}$, E11; $\boldsymbol{D})$ Student's $t$ test: ${ }^{*} 0.02,0.037(\boldsymbol{C})$; and ${ }^{*} 0.019,0.038$ (D). Error bar indicates SEM.

HDAC2 can have distinct primary functions, they efficiently compensate for the loss of each other (Jacob et al., 2011). Therefore, we depleted both HDACs in neural crest cells. To this end, we crossed mice carrying floxed Hdacl and floxed Hdac2 (Yamaguchi et al., 2010) and expressing the Cre recombinase under control of the Wnt1 promoter (Wnt1-Cre; Danielian et al., 1998). Although no detectable reduction of HDAC1/2 protein levels was observed at E9.5, HDAC1/2 were efficiently ablated at E10 from DRG and peripheral nerves of double HDAC1/HDAC2 homozygous knock-out embryos (dKO, Fig. 6A). For in vivo fate mapping of neural crest cells, we included a Cre-dependent $L a c Z$ reporter allele on $\mathrm{dKO}$ and control embryos. Although smaller than in control embryos, DRG were formed in dKO embryos at E10.5 and E11.5, as well as peripheral nerves (Fig. 6B). These findings indicate that neural crest migration was not massively affected by the loss of HDAC1 and HDAC2. Consistent with our cell culture data, Sox10 protein levels were robustly decreased at E10.5 and E11 in dKO DRG compared with controls (Fig. 6C). Although the number of apoptotic cells in DRG was increased in dKO embryos at E10.5 and E11, Sox10-positive cells in control DRG (normal Sox10 levels) or in dKO DRG (low Sox10 levels) were rarely positive for cleaved Caspase 3 (Fig. 6D). We conclude that cells expressing Sox10 at detectable levels in dKO DRG did not undergo increased apoptosis. Pax3 was present in Sox10-expressing cells of control DRG, but absent in cells of dKO DRG (Fig. 6C). We confirmed this absence by in situ hybridization (Fig. 6E). Also consistent with our in vitro data, Fabp7 and P0 transcripts, expressed in DRG and/or peripheral nerves, were not detected in 
these structures in $\mathrm{dKO}$ embryos (Fig. $6 F, G)$. Similar to dKO embryos, Sox 10 and Fabp7 expressions were strongly reduced in Wnt1-Cre Pax3 knock-out DRG (Fig. $7 A, B$ ) and DRG were smaller (Olaopa et al., 2011 and data not shown).

\section{HDAC1/2 are not essential for overall sensory neurogenesis or for differentiation of cardiac neural crest cells}

To determine whether HDAC1/2 are also required for specification of neural crest cells into sensory neurons or cardiac neural crest, we used specific markers of neurons in DRG and of differentiated cardiac neural crest cells in the heart outflow tract of $\mathrm{dKO}$ and control embryos.

There are two waves of sensory neurogenesis, the first occurring at E9.5 and the second at E10 in mouse embryos (Ma et al., 1999). Newborn sensory neurons express the transient marker NeuroD1 and the pan-sensory neuronal marker Islet1. Therefore, at E10.5, sensory neurons generated during the first wave express Islet1, but do not express NeuroD1 anymore, whereas sensory neurons of the second wave are NeuroD1 and Islet1 positive. At E10 and E10.5, we detected both NeuroD1/Islet1-double positive cells and Islet1-positive/NeuroD1-negative cells in DRG of dKO embryos and controls (Fig. 8A). We cannot address whether HDAC1/2 are necessary for the first wave of sensory neurogenesis because onset of HDAC1/2 loss in $\mathrm{dKO}$ neural crest cells is at E10. However, we can state that specification of neural crest cells into sensory neurons of the second wave occurs in the absence of HDAC1/2. Nevertheless, the number of sensory neurons was reduced in $\mathrm{dKO}$ DRG compared with controls (data not shown). Islet1-positive cells were rarely positive for cleaved caspase 3 (cCasp3; Fig. 8B) in DRG of E10.5 dKO. Therefore, specified sensory neurons did not undergo massive apoptosis. Rather, the reduced number of sensory neurons may be explained by reduced proliferation of DRG sensory neurons in the absence of HDAC1/2 (data not shown).

In vivo fate mapping revealed that cardiac neural crest cells were also able to migrate to the branchial arches and the heart outflow tract and to differentiate in the absence of HDAC1/2, as shown by $\mathrm{X}-\mathrm{Gal}$ staining and the expression of the differentiation markers Sox9 and smooth-muscle actin (SMA) in $\mathrm{dKO}$ and control embryos carrying also the Cre-dependent LacZ allele (Fig. $8 C$ ). However, the number of cardiac neural crest cells was reduced, possibly due to increased apoptosis, as detected by cCasp3 stainings in dKO branchial arches and heart outflow tracts compared with controls (Fig. $8 C)$.

\section{Discussion}

Schwann cells, the myelinating cells of the PNS, are essential for the survival and the functions of peripheral neurons. In addition, Schwann cells are remarkably plastic, which enables them to foster axonal regeneration after a lesion. Because of their exceptional regenerative properties, Schwann cells are under consideration in transplantation paradigms when large lesions of the PNS have occurred and for regeneration of lesions in the CNS. To use these cells in regenerative medicine, it is critical to know how to control their cell cycle and to understand how they specify and differentiate, all the more so because stem cells are often used to generate Schwann cells for transplantation.

Specification of neural crest cells into Schwann cells and satellite glia requires the transcription factor Sox10 (Britsch et al., 2001). However, all neural crest cells express Sox10 and the mechanisms that drive neural crest cells into the peripheral glia lineage remain unclear. The aim of this study was to elucidate these mechanisms. By combining the use of the JoMal neural crest cell line, mouse neural crest explant cultures, and mouse genetics, we demonstrate that HDAC1/2 are essential transcriptional regulators of neural crest specification into Schwann cells and satellite glia.

HDACs are chromatin-remodeling enzymes that control DNA access for the transcriptional machinery by removing acetyl groups from histone tails. DNA is negatively charged and histones are positively charged. The addition of acetyl groups to histone tails neutralizes their positive charges. This leads to less interaction between DNA and histones, thereby resulting in a more relaxed chromatin that facilitates the access for transcription factors. In contrast, when acetyl groups are removed by HDACs from histone tails, histones recover their positive charges, which leads to a tightly wound DNA around histones that results in a more condensed chromatin. Because histone deacetylation favors chromatin compaction, HDACs are commonly seen as transcriptional repressors. However, the effect of HDACs on chromatin compaction is more complex. Indeed, many lysine residues of histones can be acetylated or deacetylated, allowing for different degrees of chromatin compaction. It is thus conceivable that, depending on the degree of chromatin compaction, HDACs can either block DNA access for the transcriptional machinery and thereby silence gene expression or only limit this access for selected transcription factors to induce expression of specific genes or activation of specific gene loci. Another mechanism by which HDACs control transcription at the chromatin level has been demonstrated in a study by Wang et al. (2009) showing that HATs and HDACs act in concert to maintain genes in a transcriptionally active state. Therefore, HDACs do not always repress transcription, but can also be necessary for transcriptional activity. Our previous work shows that HDAC1/2 bind to the Sox10 promoter and the 
A

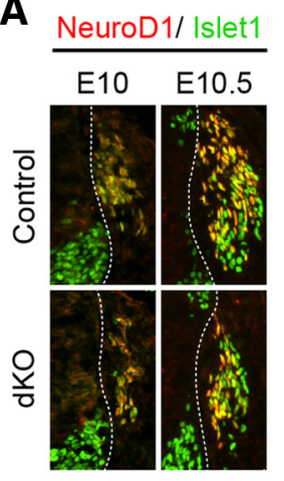

B

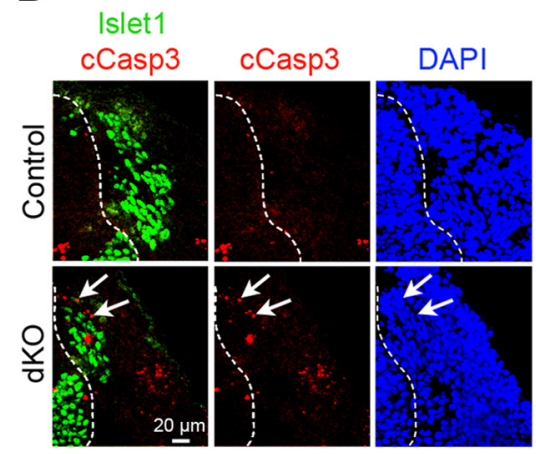

C
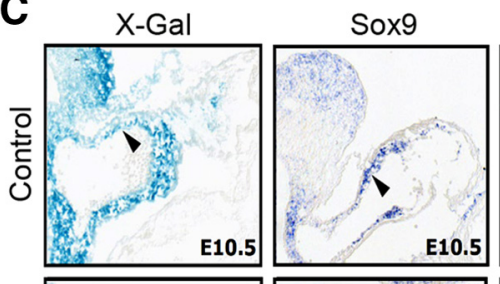

SMA/cCasp3 DAPI
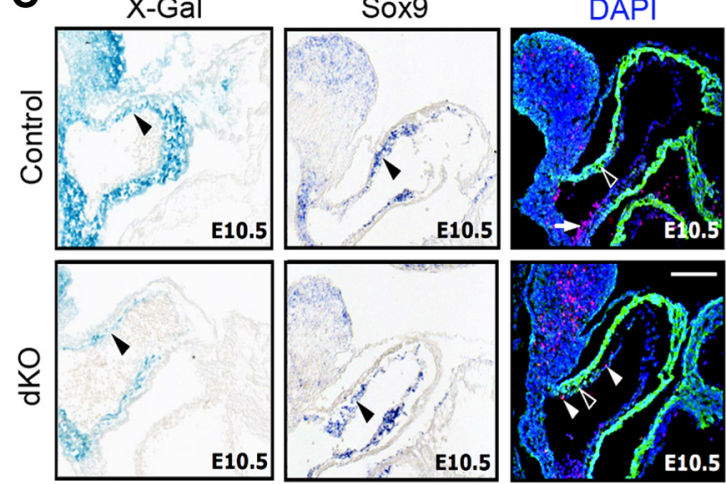

Figure 8. In the absence of $H D A C 1 / 2$, sensory neurons are specified and cardiac neural crest cells express differentiation markers. $A$, Confocal pictures of NeuroD1 (red) and Islet1 (green) coimmunofluorescence in E10 and E10.5 control and HDAC1/2 dKO DRG. Overlay of NeuroD1 and Islet 1 appears yellow. $\boldsymbol{B}$, Confocal pictures of Islet 1 (green) and cCasp3 (red) coimmunofluorescence and DAPI (blue) labeling in E10.5 control and HDAC1/2 dKO DRG. White arrows indicate cCasp3-positive DRG cells. C, In vivo cell fate mapping by X-Gal staining (black arrowheads) using the recombination-dependent Rosa26-lacZ reporter allele, Sox9 in situ hybridization (black arrowheads), and SMA (green, open arrowheads), cCasp3 (red, white arrowheads) C0immunofluorescence, and DAPI (blue) labeling in E10.5 control and HDAC1/2 dKO heart outflow tract. The white arrow shows nonspecific auto-fluorescence signal. Scale bar, $100 \mu \mathrm{m}$. For each panel, representative photographs of three controls and three dKOs for each developmental stage are shown.

Krox20 MSE in postnatal Schwann cells to activate the transcription of their genes and are therefore essential for the myelination process (Jacob et al., 2011). In addition to their effect at the chromatin level, HDACs are also able to deacetylate nonhistone targets, including several transcription factors, to modulate their activity. HDACs are thus very potent transcriptional regulators that can act at different levels.

There are 18 known mammalian HDACs that are subdivided into four classes based on their structure. HDAC1 and HDAC2 belong to class I and are almost exclusively found in the nuclear compartment. These two HDACs are highly homologous and many studies have reported that they efficiently compensate for the loss of each other, even though they can have distinct primary functions when expressed at normal levels (Jacob et al., 2011). Because HDAC1/2 were robustly expressed at the time of glia specification in mouse DRG and were upregulated in JoMa1 neural crest cells upon induction of specification into glia, we became interested in the potential functions of these two HDACs in the specification of neural crest cells into peripheral glia. During specification, Sox10 expression is maintained in the glial lineage, whereas it is downregulated in other neural-crest-derived lineages. We found that HDAC1/2 deacetylase activity is required to maintain high Sox10 levels and for expression of Pax3 in neural crest explants during specification into glia. Pax3 is also a critical transcription factor for neural crest cells and neural-crest-derived structures. Consistent with our data using a specific HDAC1/2 inhibitor in neural crest explants, in vivo genetic ablation of $\mathrm{HDAC} 1 / 2$ in neural crest cells resulted in strongly reduced Sox10 levels, no detectable Pax3 expression, and no expression of early determinants of Schwann cells and satellite glia in mouse DRG and peripheral nerves. In contrast, other neural-crestderived lineages, such as sensory neurons and those in the cardiac neural crest, although reduced in number, were specified in DRG and the branchial arches and heart outflow tract, respectively. This finding is consistent with the study of Ignatius et al. (2013) showing that DRG neurons are specified in HDAC1 mutant zebrafish, but are reduced in number, particularly in the tail, and appears in partial contrast to the absence of differentiation of cardiac neural crest in the branchial arches of HDAC1 mutant zebrafish (Ignatius et al., 2013).

To analyze the molecular mechanisms of $\mathrm{HDAC} 1 / 2$ functions in the specification of peripheral glia, we used the JoMal neural crest cell line that can be differentiated into glia. In contrast to postnatal Schwann cells, HDAC1/2 were not able to directly activate Sox10 transcription in JoMa1 neural crest cells. Instead, we identified Pax3 as a critical target gene for $\mathrm{HDAC1} / 2$-dependent control of peripheral glia specification. Indeed, HDAC2 and Sox 10 were bound to and activated the Pax3 promoter in JoMa1 neural crest cells. Of note, the $1.6 \mathrm{~kb}$ Pax3 promoter contains two known neural crest enhancer (NCE) regions (Milewski et al., 2004). However, there are many putative binding sites for Sox10 in the Pax3 promoter. They are located in the NCEs, but also outside of the NCE regions. For this reason, we did not analyze the binding of HDAC2/Sox10 complexes to the NCEs in particular, but to the Pax3 promoter in general.

Our study shows that Sox 10 recruits HDAC1/2 to the Pax3 and $P 0$ promoters in neural crest cells to induce their transcription and that $\mathrm{HDAC} 1 / 2$ are essential for expression of these target genes. In turn, Pax3 binds to and activates the Sox10 MCS4 enhancer that is critical for Sox10 expression in neural crest cells during specification of the glial lineage (Wahlbuhl et al., 2012). Pax3 is necessary to maintain high Sox10 levels and therefore to trigger appropriate expression of the early determinants of Schwann cells and satellite glia. In the absence of HDAC1/2 in neural crest cells, Sox10 is strongly reduced, but still expressed in DRG, indicating that expression of Sox10 in neural crest cells is not only dependent on HDAC1/2 and Pax3, but also on other factors, as suggested by the multiple binding sites for several transcription factors located on Sox10 MCS4 (Werner et al., 2007; Wahlbuhl et al., 2012). However, we demonstrate that HDAC1/ 2-dependent control of Sox10 MCS4 activity is mediated by Pax3. In addition to controlling Pax3 expression, we found that HDAC1/2 also control P0 expression directly. Therefore, HDAC1/2 induce the specification of neural crest cells into peripheral glia by controlling the expression of the transcription factors necessary for this process, but also the expression of some of their key target genes.

We show that the Sox10 MCS4 enhancer is active in JoMa1 neural crest cells, whereas the Sox 10 promoter is not. In contrast, the Sox10 promoter is active in postnatal Schwann cells, whereas the Sox10 MCS4 enhancer is not. These different activities of gene regulatory regions depending on the developmental stage are likely due to the availability and/or recruitment of different cofactors at these distinct stages. Different Sox10-HDAC1/2 complexes must thus be formed and recruited to distinct gene regulatory regions. Although challenging, it will be very interesting to identify other potential binding partners of the distinct Sox10-HDAC1/2 complexes at different developmental stages of 
the Schwann cell lineage that may be responsible for the recruitment of these complexes to different gene regulatory regions.

In summary, we demonstrate that $\mathrm{HDAC} 1 / 2$ are required for Pax 3 expression in neural crest cells and that Pax 3 is necessary for HDAC2-dependent control of Sox10 levels and expression of early determinants of Schwann cells and satellite glia. In addition, $\mathrm{HDAC} 1 / 2$ control the expression of $\mathrm{P} 0$ directly. By regulating the interplay between Sox10 and Pax3 and the expression of their target genes, HDAC1/2 are thus essential for specification of neural crest cells into peripheral glia.

\section{References}

Antonellis A, Huynh JL, Lee-Lin SQ, Vinton RM, Renaud G, Loftus SK, Elliot G, Wolfsberg TG, Green ED, McCallion AS, Pavan WJ (2008) Identification of neural crest and glial enhancers at the mouse Sox10 locus through transgenesis in zebrafish. PLoS Genet 4:e1000174. CrossRef Medline

Auerbach R (1954) Analysis of the developmental effects of a lethal mutation in the house mouse. Journal of Experimental Zoology 127:305-329. CrossRef

Britsch S, Goerich DE, Riethmacher D, Peirano RI, Rossner M, Nave KA, Birchmeier C, Wegner M (2001) The transcription factor Sox10 is a key regulator of peripheral glial development. Genes Dev 15:66-78. CrossRef Medline

Campeau E, Ruhl VE, Rodier F, Smith CL, Rahmberg BL, Fuss JO, Campisi J, Yaswen P, Cooper PK, Kaufman PD (2009) A versatile viral system for expression and depletion of proteins in mammalian cells. PLoS One 4:e6529. CrossRef Medline

Danielian PS, Muccino D, Rowitch DH, Michael SK, McMahon AP (1998) Modification of gene activity in mouse embryos in utero by a tamoxifen-inducible form of Cre recombinase. Curr Biol 8:1323-1326. CrossRef Medline

de Ruijter AJ, van Gennip AH, Caron HN, Kemp S, van Kuilenburg AB (2003) Histone deacetylases (HDACs): characterization of the classical HDAC family. Biochem J 370:737-749. CrossRef Medline

Doddrell RD, Dun XP, Moate RM, Jessen KR, Mirsky R, Parkinson DB (2012) Regulation of Schwann cell differentiation and proliferation by the Pax-3 transcription factor. Glia 60:1269-1278. CrossRef Medline

Epstein JA, Lam P, Jepeal L, Maas RL, Shapiro DN (1995) Pax3 inhibits myogenic differentiation of cultured myoblast cells. J Biol Chem 270: 11719-11722. Medline

Franz T (1990) Defective ensheathment of motoric nerves in the Splotch mutant mouse. Acta Anat 138:246-253. CrossRef Medline

Glozak MA, Sengupta N, Zhang X, Seto E (2005) Acetylation and deacetylation of non-histone proteins. Gene 363:15-23. CrossRef Medline

Greenwood AL, Turner EE, Anderson DJ (1999) Identification of dividing, determined sensory neuron precursors in the mammalian neural crest. Development 126:3545-3559. Medline

Hagedorn L, Suter U, Sommer L (1999) P0 and PMP22 mark a multipotent neural crest-derived cell type that displays community effects in response to TGF-beta family factors. Development 126:3781-3794. Medline

Hari L, Miescher I, Shakhova O, Suter U, Chin L, Taketo M, Richardson WD, Kessaris N, Sommer L (2012) Temporal control of neural crest lineage generation by Wnt $/ \beta$-catenin signaling. Development 139:2107-2117. CrossRef Medline

Ignatius MS, Unal Eroglu A, Malireddy S, Gallagher G, Nambiar RM, Henion PD (2013) Distinct functional and temporal requirements for zebrafish Hdacl during neural crest-derived craniofacial and peripheral neuron development. PLoS One 8:e63218. CrossRef Medline

Jacob C, Christen CN, Pereira JA, Somandin C, Baggiolini A, Lötscher P, Ozçelik M, Tricaud N, Meijer D, Yamaguchi T, Matthias P, Suter U (2011) HDAC1 and HDAC2 control the transcriptional program of myelination and the survival of Schwann cells. Nat Neurosci 14:429-436. CrossRef Medline

Jessen KR, Mirsky R (2005) The origin and development of glial cells in peripheral nerves. Nat Rev Neurosci 6:671-682. CrossRef Medline

Kioussi C, Gross MK, Gruss P (1995) Pax3: a paired domain gene as a regulator in PNS myelination. Neuron 15:553-562. CrossRef Medline

Kuhlbrodt K, Herbarth B, Sock E, Hermans-Borgmeyer I, Wegner M (1998) Sox10, a novel transcriptional modulator in glial cells. J Neurosci 18:237250. Medline

Kurtz A, Zimmer A, Schnütgen F, Brüning G, Spener F, Müller T (1994) The expression pattern of a novel gene encoding brain-fatty acid binding protein correlates with neuronal and glial cell development. Development 120:2637-2649. Medline

Lang D, Epstein JA (2003) Sox10 and Pax3 physically interact to mediate activation of a conserved c-RET enhancer. Hum Mol Genet 12:937-945. CrossRef Medline

Ma Q, Fode C, Guillemot F, Anderson DJ (1999) Neurogenin1 and neurogenin2 control two distinct waves of neurogenesis in developing dorsal root ganglia. Genes Dev 13:1717-1728. CrossRef Medline

Maurer J, Fuchs S, Jäger R, Kurz B, Sommer L, Schorle H (2007) Establishment and controlled differentiation of neural crest stem cell lines using conditional transgenesis. Differentiation 75:580-591. CrossRef Medline

Michan S, Sinclair D (2007) Sirtuins in mammals: insights into their biological function. Biochem J 404:1-13. CrossRef Medline

Milewski RC, Chi NC, Li J, Brown C, Lu MM, Epstein JA (2004) Identification of minimal enhancer elements sufficient for Pax3 expression in neural crest and implication of Tead2 as a regulator of Pax3. Development 131:829-837. CrossRef Medline

Olaopa M, Zhou HM, Snider P, Wang J, Schwartz RJ, Moon AM, Conway SJ (2011) Pax3 is essential for normal cardiac neural crest morphogenesis but is not required during migration nor outflow tract septation. Dev Biol 356:308-322. CrossRef Medline

Paratore C, Suter U, Sommer L (1999) Embryonic gene expression resolved at the cellular level by fluorescence in situ hybridization. Histochem Cell Biol 111:435-443. CrossRef Medline

Paratore C, Goerich DE, Suter U, Wegner M, Sommer L (2001) Survival and glial fate acquisition of neural crest cells are regulated by an interplay between the transcription factor Sox10 and extrinsic combinatorial signaling. Development 128:3949-3961. Medline

Peirano RI, Wegner M (2000) The glial transcription factor Sox10 binds to DNA both as monomer and dimer with different functional consequences. Nucleic Acids Res 28:3047-3055. CrossRef Medline

Peirano RI, Goerich DE, Riethmacher D, Wegner M (2000) Protein zero gene expression is regulated by the glial transcription factor Sox10. Mol Cell Biol 20:3198-3209. CrossRef Medline

Prasad MK, Reed X, Gorkin DU, Cronin JC, McAdow AR, Chain K, Hodonsky CJ, Jones EA, Svaren J, Antonellis A, Johnson SL, Loftus SK, Pavan WJ, McCallion AS (2011) SOX10 directly modulates ERBB3 transcription via an intronic neural crest enhancer. BMC Dev Biol 11:40. CrossRef Medline

Sanchez-Ferras O, Coutaud B, Djavanbakht Samani T, Tremblay I, Souchkova O, Pilon N (2012) Caudal-related homeobox (Cdx)-dependent integration of canonical Wingless/intl-related (Wnt) signals on a well-conserved neural crest enhancer of the proximal Paired-box 3 (Pax3) promoter. J Biol Chem 287:16623-16635. CrossRef Medline

Shah NM, Marchionni MA, Isaacs I, Stroobant P, Anderson DJ (1994) Glial growth factor restricts mammalian neural crest stem cells to a glial fate. Cell 77:349-360. CrossRef Medline

Soriano P (1999) Generalized lacZ expression with the ROSA26 Cre reporter strain. Nat Genet 21:70-71. CrossRef Medline

Stemple DL, Anderson DJ (1992) Isolation of a stem cell for neurons and glia from the mammalian neural crest. Cell 71:973-985. CrossRef Medline

Wahlbuhl M, Reiprich S, Vogl MR, Bösl MR, Wegner M (2012) Transcription factor Sox 10 orchestrates activity of a neural crest-specific enhancer in the vicinity of its gene. Nucleic Acids Res 40:88-101. CrossRef Medline

Wang Z, Zang C, Cui K, Schones DE, Barski A, Peng W, Zhao K (2009) Genome-wide mapping of HATs and HDACs reveals distinct function in active and inactive genes. Cell 138:1019-1031. CrossRef Medline

Werner T, Hammer A, Wahlbuhl M, Bösl MR, Wegner M (2007) Multiple conserved regulatory elements with overlapping functions determine Sox10 expression in mouse embryogenesis. Nucleic Acids Res 35:65266538. CrossRef Medline

Yamaguchi T, Cubizolles F, Zhang Y, Reichert N, Kohler H, Seiser C, Matthias P (2010) Histone deacetylases 1 and 2 act in concert to promote the G1-to-S progression. Genes Dev 24:455-469. CrossRef Medline

Yao YL, Yang WM (2011) Beyond histone and deacetylase: an overview of cytoplasmic histone deacetylases and their nonhistone substrates. J Biomed Biotechnol 2011:146493. CrossRef Medline

Zhang J, Xu F, Hashimshony T, Keshet I, Cedar H (2002) Establishment of transcriptional competence in early and late $S$ phase. Nature 420:198202. CrossRef Medline 